\title{
Impact of Long-Term Weathering on the Properties of a Digestate- Based Biocomposite
}

\author{
Marion Gebhardt ${ }^{1} \cdot$ Markus Milwich $^{1} \cdot$ Götz T. Gresser ${ }^{1,2} \cdot$ Andreas Lemmer $^{3}$
}

Received: 8 June 2021 / Revised: 3 September 2021 / Accepted: 7 September 2021 / Published online: 5 November 2021

(c) The Author(s) 2021

\begin{abstract}
Natural fibre composites are increasingly used. For many applications, the long-term stability of the mechanical properties is crucial. Therefore, the effects of weathering of a biocomposite made from fibrous digestate and bio-based thermoset are investigated. The fibre component of the composite comes from digestate of a German biogas station which processes hop vines as main substrate. The matrix is a plant-oil-based epoxy resin. The samples were alternately exposed to UV radiation and moisture for various lengths of time. Afterwards, the material strength and water absorption were tested. As a result, the weathering leads to a decrease of strength but not to a high increase of water uptake.
\end{abstract}

Keywords Agricultural waste $\cdot$ Accelerated weathering $\cdot$ Bio-composites $\cdot$ Sustainability $\cdot$ Biogas

\section{Introduction}

\section{Natural Fibre Composites}

Fibre-reinforced plastics consist of a fibre component and a plastic matrix. The fibres are usually present as a textile and absorb the tensile and flexural forces. The matrix protects against environmental influences and gives the material its shape . Natural fibres are more and more used in composites. Especially natural plant fibres are increasingly used due to their good specific properties and their ecological advantages, compared to synthetic fibres (Riedel and Nickel 2000). Examples for the use of natural fibres as reinforcement in composites are natural fibre reinforced composites (NFRP) with so called endless fibres like woven or nonwovens. A further example, are the wood plastic composites (WPC) (Carus et al. 2015). WPC are mostly made of synthetic thermoplastic

This article is part of the Topical Collection on Natural Fibers: Materials of the Future

Marion Gebhardt

marion.gebhardt@ditf.de

1 Institute for Textile and Fiber Research, Körschtalsstraße 26, 73770 Denkendorf, Germany

2 Institute for Textile and Fiber Technologies, University of Stuttgart, Stuttgart, Germany

3 State Institute of Agricultural Engineering and Bioenergy, University Hohenheim, Stuttgart, Germany polymers and wood fibre, particle or flour. Although natural fibres are renewable, the fact that they are specially cultivated makes them less sustainable than they could be (Grundmann 2007; Gessner 1955; Rana 2014). There is a lot of research to use alternative fibre sources, such as fibrous waste materials like wooden saw dust, coconut fibre or invasive plants (Fitri et al. 2017; Dhakal et al. 2018; Bradley and Conroy 2019).

\section{Durability of Composites in General}

One main objective of sustainable materials is that they are made from environmentally friendly raw materials with low energy costs. Another important thing is that the product life time is as long as possible. In case of plastics and reinforced plastics, the durability is important. Plastics do not have an unlimited shelf life. Environmental influences cause irreversible changes in their chemical and mechanical properties (Bonnet 2009). Ageing of polymers is a complex process and is divided into chemical and physical ageing, where the physical ageing leads to decreasing mechanical properties (Barbosa 2017). This is the interesting type of ageing for the presented study. The ageing of fibre-reinforced composites is dominated by the ageing of the polymer (Blaga 1978; Kammerhofer 2018). Thermoset polymers are not sensitive to environmental influences, except of UV radiation. The presence of UV radiation and oxygen leads to photooxidative degradation. In general, polymers with higher service temperature show a better UV stabilisation (Bonnet 2009). For thermoset polymers, 
the glass transition temperature is an indication for the service temperature (Schürmann 2007).

Epoxy resins loose mechanical properties after exposure to environmental influences because of matrix degradation (Pschorr and Cianciarulo 1965; Kumar et al. 2002). Epoxy coatings show the same behaviour (Kotnarowska 1999). Roylance and Roylance (1978) made weathering tests with glass-fibre-epoxy-composites. The used epoxy has a glass transition temperature from $180^{\circ} \mathrm{C}$. After storage at the outside in the city panama (hot-wet), the tensile strength decreased to $70 \%$ of the original strength (Roylance and Roylance 1978). Information on the sunshine duration and rain fall is not given. Accelerated weathering tests from Cysne Barbosa (2017) do not show any influence on the breaking force of carbon fibre-reinforced plastics after weathering for 3 months (Barbosa 2017). In both studies' high performance, endless fibre reinforcements are used.

\section{Durability of Natural Fibre Reinforced Plastics}

As example of natural fibre-reinforced plastics with outdoor applications, WPC are investigated in different studies. There is no clear information about the ageing of WPC, because it depends on the material and additives. It is found that WPC (wood and polyethylen) loses approx. $30 \%$ of the original stiffness after $2000 \mathrm{~h}$ of weathering with UV and moisture. The composite surface is rougher after the weathering periods than before. Friedrich and Luible (2016) summarize different studies on accelerated weathering of WPC. They point out that the strength of the materials decreases through artificial weathering, even if the values differ depending on the used material and weathering method (Friedrich and Luible 2016). The ageing of Jute-epoxy-composites was investigated by Nizin (2019). The material shows $33 \%$ of the original strength after 12 months of outdoor storage.

Natural fibre composites have the major disadvantage that they are hygroscopic. The swelling of the fibre causes a degradation of the composite (Koolen and van Vuure 2019). Special fibre treatments and a complete enclosure with the polymer matrix help to prevent water absorption.

Natural fibres are lignocellulosic materials with cellulose being the main component in most of the classic fibres with textile use. Most of the fibre plants are nonwooden plants, and lignin makes only a small part of the fibres. In wooden plants, the lignin content is 20 to $35 \%$ depending on the origin tree of the wood (Knackstedt 1939). On the other hand, Lignin is a natural UV absorber which leads to a good UV stability of wood (Sadeghifar and Ragauskas 2020; Wang et al. 2019; Sandermann and Sehlumbom 1962).

\section{Motivation and Goal}

Composites based on digestate from biogas stations (agricultural waste) appear very advantageous from an ecological point of view. While the production of these composites has already been described in single articles, all information about the long-term stability of such materials and their potential product lifetime is missing so far. The knowledge about the stability and potential product lifetime is important for estimating the sustainability of the new material because sustainability has three parts: ecology, economy and sociology. The origin of material and its processing is important for the ecology of a product (Pufe 2012). For the social acceptance and the economic part, the lifetime plays a major role.

To focus more on the social and economic parts of sustainability, the United Nations General Assembly set 17 sustainable development goals. These goals should lead to a better future for all people. The goals are: No Poverty, Zero Hunger, Good Health and Well-being, Quality Education, Gender Equality, Clean Water and Sanitation, Affordable and Clean Energy, Decent Work and Economic Growth, Industry, Innovation and Infrastructure, Reducing Inequality, Sustainable Cities and Communities, Responsible Consumption and Production, Climate Action, Life Below Water, Life on Land, Peace, Justice, and Strong Institutions, Partnerships for the Goals (United Nations 2021). The digestate composite helps to avoid over fertilization and this leads to less pollution of ground water. In this work, the weather stability is investigated. The goal of the presented work is to observe the environmental durability of the digestate composite by weathering tests to get more data for assessing the sustainability and possible applications of this new material. The study should answer the question, if the developed composite can address the goal of responsible consumption and production.

\section{Material and Methods}

\section{Material}

The investigated biocomposites consist of a bio-based matrix and specially treated solid fraction of digestate. Digestate is a fibrous agricultural waste from biogas plants with a dry matter content less than $15 \%$. Using a screw press, the digestate can be separated in a liquid fraction, which is used as fertilizer, and a solid, fibrous fraction, which can be used as fibre reinforcement for composites. The composition of the digestate is highly dependent on the input materials used in the station. The biogas 
plant from which the digestate was obtained mainly uses chopped hop vines, and smaller amounts of grass silage and maize, which resulted in a solid phase with a high fibre content after separation. The solid fraction of digestate is washed, grinded, dried and sieved before using for the composite production. The solid fraction of the digestate has a lignin and cellulose content of approximately $30 \%$. The material is called digestate fibre because after washing and grinding, most particles have a significantly higher length than width. The main part of the cleaned digestate fibres has a length between 2 and $17 \mathrm{~mm}$, with a density of $1.46 \mathrm{gcm}^{-3}$ (Gebhardt, in press). The digestate is further processed to a wet laid nonwoven with pulp as binder leading to a completely bio-based material. The process is similar to paper making and the resulting nonwoven is completely bio-based.

The matrix is a vegetable oil-based epoxy system with $100 \%$ bio-based carbon in the resin component. As main component of the hardener is a polycarboxylic acid anhydride. The viscosity at $120^{\circ} \mathrm{C}$ is $20 \mathrm{mPa} \cdot \mathrm{s}$, which is advantageous for the pressing process. The glass transition temperature is $110^{\circ} \mathrm{C}$. The curing temperature of the resin system is between $100^{\circ} \mathrm{C}$ and $190^{\circ} \mathrm{C}$ and the curing time depends on the temperature. With higher temperature, the curing is faster.

The composite is produced by hot pressing. Two layers of nonwoven are impregnated with the matrix by hand lay-up and then put into the die. To spread the matrix and consolidate the composite, it is pressed with $155^{\circ} \mathrm{C}$ and $6 \mathrm{MPa}$ for $10 \mathrm{~min}$. The composite has a fibre-weight-ratio of approx. $40 \%$. Figure 1 shows the production process of the composites beginning from the biogas station.

\section{Methods}

To observe the durability of the composite, it is artificially weathered. The weathering is done according to ISO 4892-3 with an QUV-accelerated weathering tester by Q-Lab, Saarbrücken, Germany. The samples $(15 \times 60 \mathrm{~mm})$ are alternately exposed to UV radiation $(8 \mathrm{~h})$ and moist air $(4 \mathrm{~h})$, at room temperature over test periods of 1000 and $2000 \mathrm{~h}$. 1000-h testing with UV radiation corresponds with 1 year of sunshine in Germany. Due to the test machine, only one side of the sample is exposed to the UV radiation. In addition, an untreated, dry and dark stored sample is used as reference.

To measure the strength and the elongation after ageing, 3-point-bending-tests are made using a testing machine from ZWICK-ROELL, Ulm, Germany according to DIN EN ISO 14125. The sample size is $15 \times 60 \mathrm{~mm}$ and three repetitions are measured. The average ageing velocity is calculated as interpolation between the strength of the 0 -h weathering and the 2000-h weathering samples.

The water uptake is calculated according to DIN EN ISO 62:2008-05. The main change compared to the standard is that, additionally the water uptake after $10 \mathrm{~min}$ is measured. Small samples from the composite plates are put into deionized water for $10 \mathrm{~min}$ and $24 \mathrm{~h}$. The sample is weighed before and after storage in water. The water uptake is observed as additional test with a small sample quality (n $=3$ ); for this reason, no statistics are made.

Microscopic pictures of surfaces and cross sections were made using a KEYENCE VHX 2000, Neu-Isenburg, Germany, to observe changes in the composite structure. The observed cross section is cut and polished before weathering and not treated again.
Fig. 1 Flow diagram of the composite production out of digestate

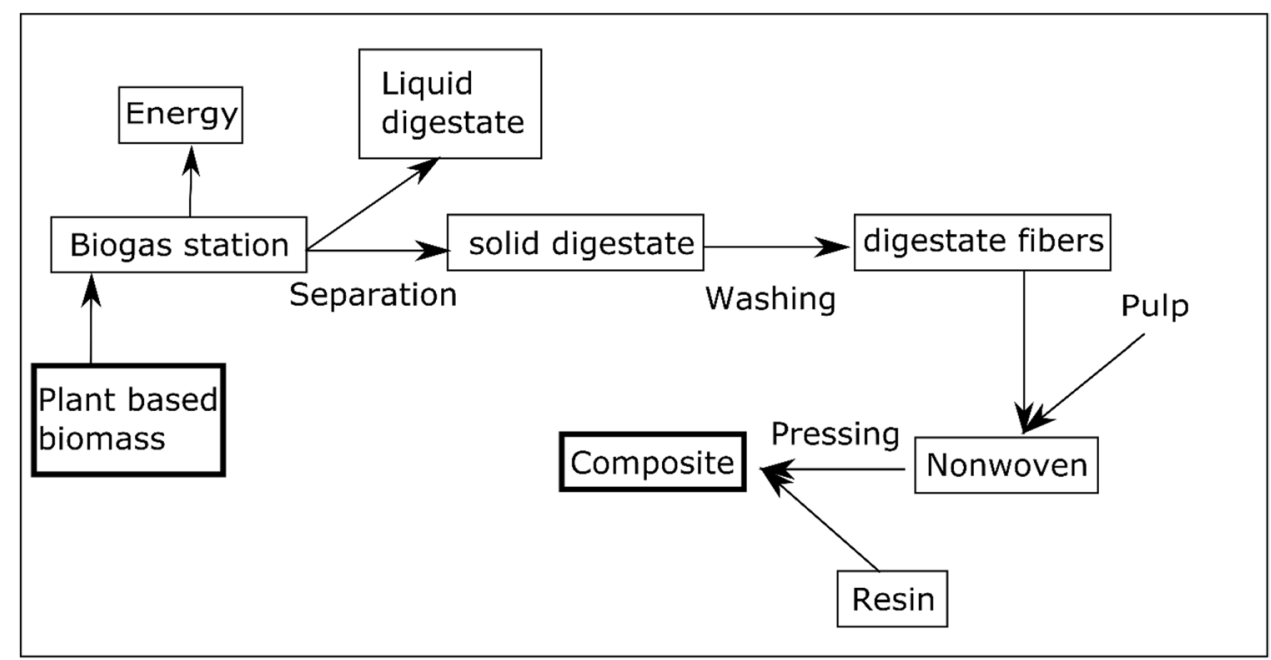




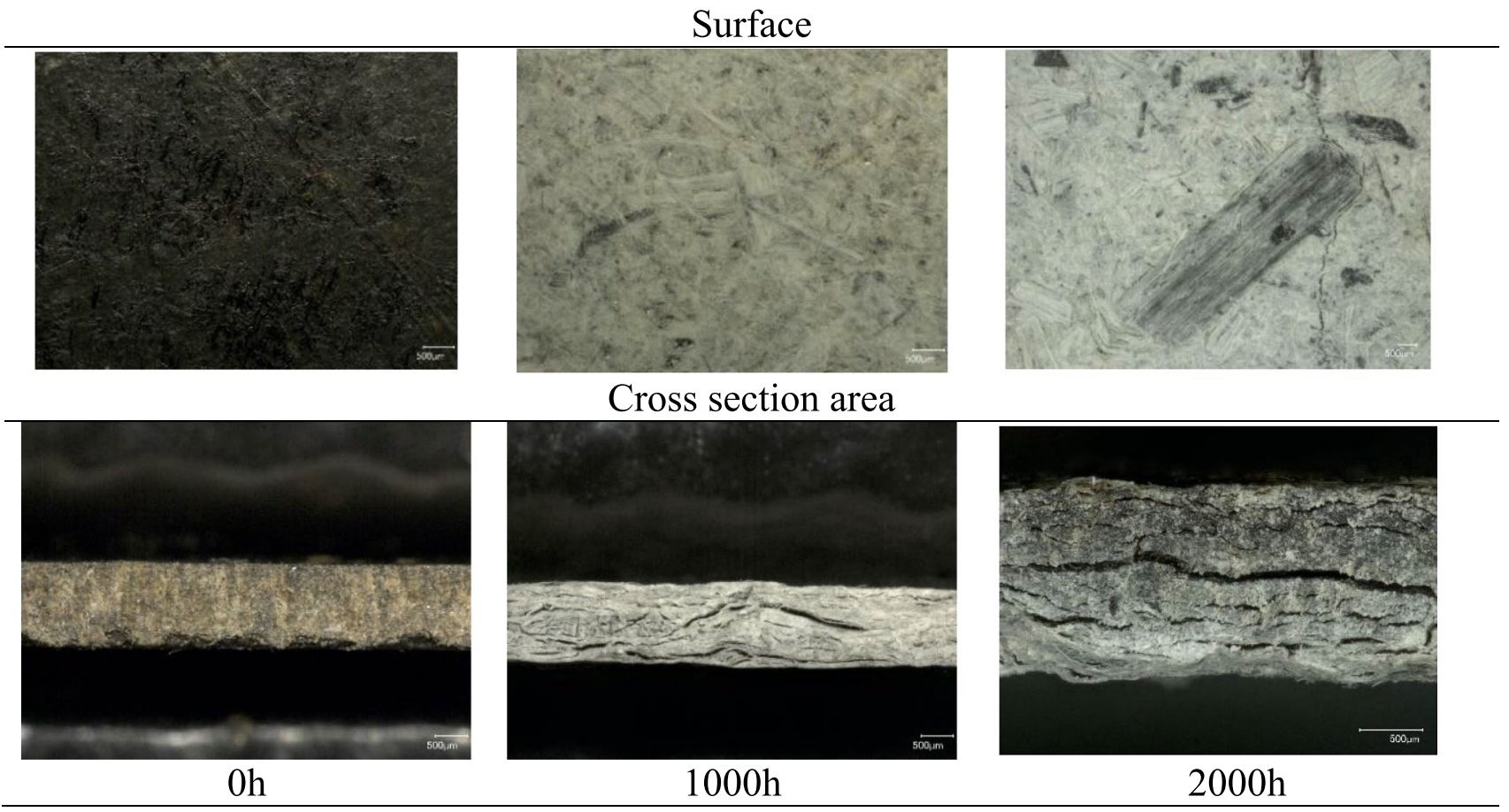

Fig. 2 Micrographs of surface and cross section of the original and weathered samples

\section{Results and Discussion}

\section{Composite Structure}

Figure 2 shows the micrographs of the surface and the cross section of the different samples. The first observation is that the surface of the exposed side is white after $1000 \mathrm{~h}$ and $2000 \mathrm{~h}$ of treatment. The surface of the weathered composite is wavy after the UV and moisture treatment but still closed, whereas the cross section shows bigger differences in the form of delamination and cracks. The damage is not only at the surface of the cross section but goes to the inside of the material and not only near the exposed surface. The cross section of the parts which are cut before the weathering are white. When comparing those visible effects on matrix and fibres, it can be stated that the colour changing and the cracks are the result of a degrading polymer matrix and that the fibre seems to be intact. As described in the literature, the observations show that the decomposition process of the composite is determined by the polymer. The relatively high lignin content of the digestate can be a reason for the stability of the fibres.

\section{Flexural Strength}

The mechanical properties of the weathered samples differ from the untreated samples; this can be taken from Figure 3 and Table 1. In Table 1, the average values are

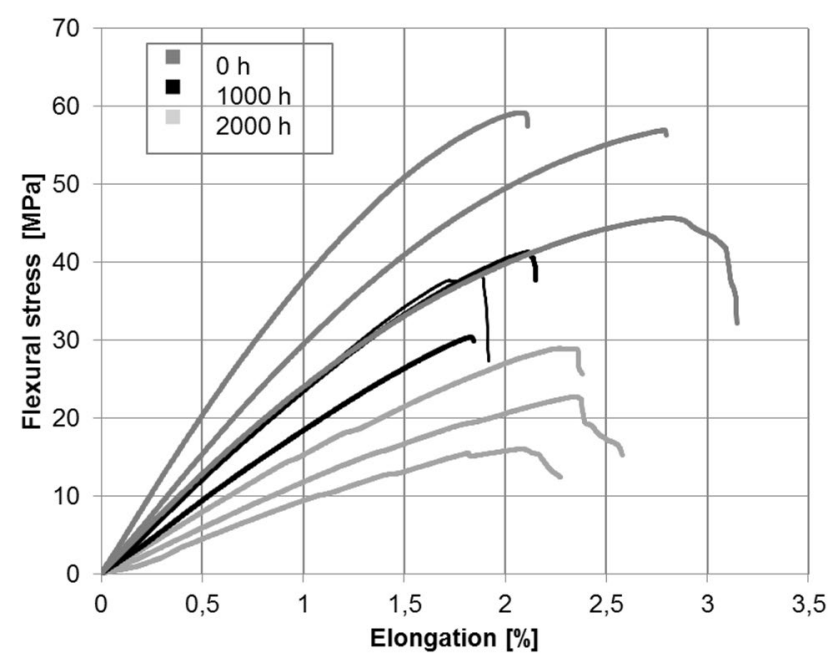

Fig. 3 Strength-elongation-diagram of the variations with $0 \mathrm{~h}, 1000 \mathrm{~h}$ and $2000 \mathrm{~h}$ of accelerated weathering. For every variation, the result of all three tested samples is plotted

Table 1 Results of the bending test: average values for E-modulus, strength and elongation

\begin{tabular}{llll}
\hline Parameter & $0 \mathrm{~h}$ & $1000 \mathrm{~h}$ & $2000 \mathrm{~h}$ \\
\hline E-Modulus [GPa] & 3.3 & 2.2 & 1.1 \\
Strength [MPa] & 54.0 & 36.7 & 22.6 \\
Elongation [\%] & 2.6 & 1.9 & 2.2 \\
\hline
\end{tabular}


given, and Figure 3 shows the strength elongation-diagrams. After a weathering period of $1000 \mathrm{~h}$, the strength is reduced to approx. $70 \%$ of the original strength and after $2000 \mathrm{~h}$, even to approx. $40 \%$. The strength can be predicted using the average ageing velocity. This leads to the equation $y=0.014 x+51$, with $\mathrm{x}$ equals the exposure duration in $\mathrm{h}$ and $\mathrm{y}$ equals the predicted strength in MPa. The elongation of the composite decreases from 2.6 to $1.9 \%$ after $1000 \mathrm{~h}$ of weathering and increases to $2.2 \%$ after the weathering of $2000 \mathrm{~h}$. The scattering of the values for the weathered samples is smaller than that of the original samples. The scattering can be seen with the help of the lines of the single samples. For the weathered samples, the lines are much closer together. UV light and humidity have no evident influence on the elongation of the examined material.

The fracture pattern is not influenced by the UV and moisture treatment. The samples show a brittle failure without splintering and a complete break. The samples show a light tendency to a more ductile behaviour after $2000 \mathrm{~h}$ of weathering.

The digestate composite shows a faster loss of strength than the materials described in the literature. The differences can be rather assigned to the polymer used than to the type of reinforcement fibre. The reaction kinetics of bio-based polymers are different to synthetic polymers so this can be a reason for the faster degradation. In comparison studies, endless fibre reinforcements are used. An endless fibre bundle of carbon or glass fibres has a

Table 2 Results of water uptake after $10 \mathrm{~min}$ and $24 \mathrm{~h}$ of the weathered and un-weathered samples

Fig. 4 Sample $2000 \mathrm{~h}$ before and after water storage. a Sample before water storage, b Sample directly after water storage (wet), c Sample after drying again for $12 \mathrm{~h}$ at room temperature

\begin{tabular}{lll}
\hline Sample & $10 \mathrm{~min}$ & $24 \mathrm{~h}$ \\
\hline $0 \mathrm{~h}$ & $2 \%$ & $10 \%$ \\
$1000 \mathrm{~h}$ & $4 \%$ & $12 \%$ \\
$2000 \mathrm{~h}$ & $6 \%$ & $13 \%$ \\
\hline
\end{tabular}

a higher strength than a nonwoven of naturals fibres. When the matrix is destroyed, the aligned fibres can better carry the load. The glass transition of the used epoxy is not very high compared to other systems which can be another explanation for the faster degradation.

The non-linear behaviour of the elongation is a result of the matrix degradation. The matrix itself has a lower elongation than the nonwoven. The nonwoven structure is still intact and the fibre seems not to be degraded. This can be a result of the high lignin content of the digestate. The nonwoven, as a textile, is able to elongate before failing. When the matrix is partly destroyed, the fibres are no longer fixed and the composite elongation is higher.

\section{Water Absorption After Weathering}

The results of the water uptake are presented in Table 2 . The 10-min water uptake shows between the three weathering conditions bigger differences than the 24-h water uptake. The 2000-h weathered sample has a higher 10-min water uptake than the untreated original sample, whereas the 24-h water uptake shows a smaller increase (from 10 to $13 \%$ ). A possible explanation could be that in case of short time water uptake, water flows fast into the cracks. This water uptake decreases over time because after initially filling the cracks, the matrix takes up water much slowly. The fibres are still surrounded with resin, so they also show a low tendency to adsorb water. Figure 4 shows a 200-h sample before and after the water storage. All pictures are taken under the same artificial light conditions. After water storage, no optical changes can be seen. The composite is not widened or deformed. This is another indication for a proper saturation with resin, even after weathering.
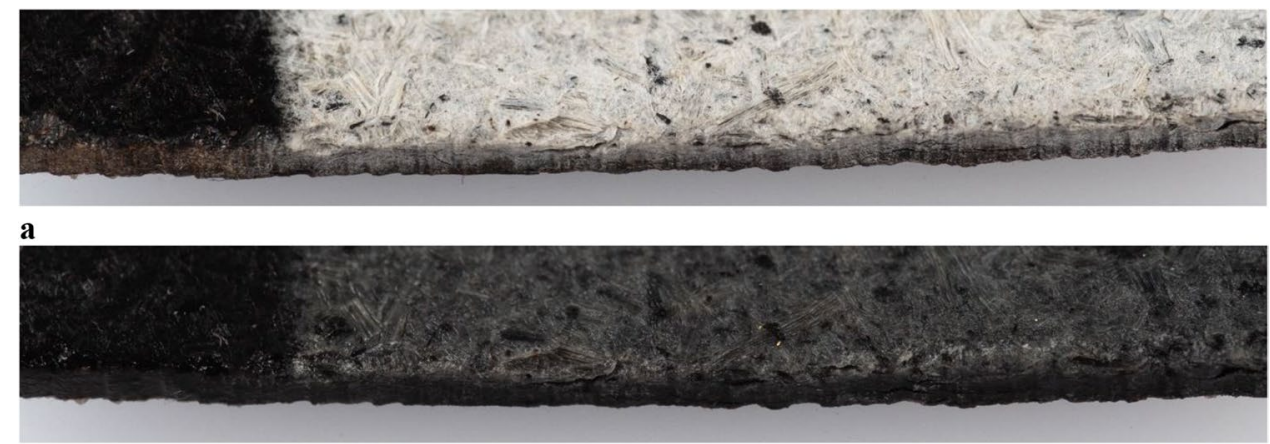

b

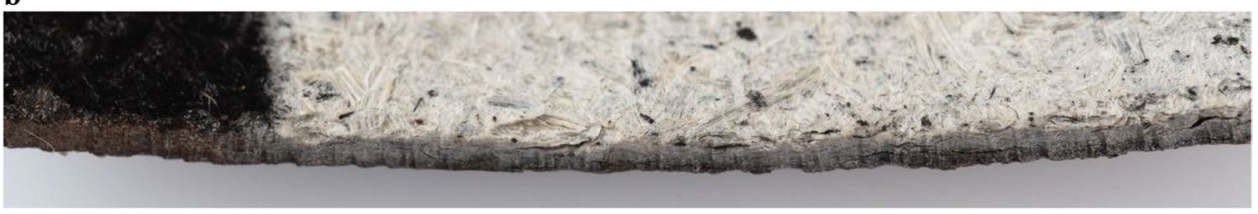

c 


\section{Influence on the Material Sustainability}

Because the sustainability is influenced by the test results, their relevance should be discussed. The high decrease of the strength leads to a restricted product use time for outdoor applications. The changes in the composite structure and surface are also reasons for a faster replacement of the material, which is a negative point regarding the sustainability. The water uptake is the only parameter, which has no negative influence. The long-time water uptake $(24 \mathrm{~h})$ is not negatively influenced by the ageing.

\section{Conclusions}

The material properties of the digestate bio epoxy composite decrease due to the accelerated weathering. As described and according to the literature, this seems to be dominated by the degrading polymer matrix. Therefore, UV stabilised matrices or the use of another matrix can enhance the durability of the composite. The fibre itself seems to have no significant influence on the weathering stability. Fibres obtained from biogas digestate can thus be an interesting starting material for the production of composites. With the material, the SDG 12 should be addressed. The fibre itself has a great potential to be a sustainable fibre resource. But, to reach the goal of a sustainable consumer product, some problems must be solved. At the present state of the development, an indoor use is preferred to address all parts of the sustainability. With additives or coatings, the weather stability can be improved. This should be investigated in further studies.

Acknowledgements The authors thank the company Q-Lab Germany for giving the opportunity to make the accelerated weathering. The research was done as addition to the ZIM-project 4060062CM9.

Author Contribution MG did the experiments and wrote the main part of the article. MM was the project coordinator and wrote parts of the article. GTG: helped planning the project and necessary experiments. AL planed the experiments. All authors read and approved the final manuscript.

Funding Open Access funding enabled and organized by Projekt DEAL. The research was done as addition to the ZIM-project 4060062CM9. The authors also thank the federal Ministry for Economic Affairs and Energy for funding this project under number 4060062 CM9.

Data Availability The datasets generated during and/or analysed during the current study are available from the corresponding author on reasonable request.

\section{Declarations}

Competing Interests The authors declare no competing interests.

Open Access This article is licensed under a Creative Commons Attribution 4.0 International License, which permits use, sharing, adaptation, distribution and reproduction in any medium or format, as long as you give appropriate credit to the original author(s) and the source, provide a link to the Creative Commons licence, and indicate if changes were made. The images or other third party material in this article are included in the article's Creative Commons licence, unless indicated otherwise in a credit line to the material. If material is not included in the article's Creative Commons licence and your intended use is not permitted by statutory regulation or exceeds the permitted use, you will need to obtain permission directly from the copyright holder. To view a copy of this licence, visit http://creativecommons.org/licenses/by/4.0/.

\section{References}

Barbosa AP, Fulco AP, Guerra ES, Arakaki FK, Tosatto M, Costa MC, Melo J, Blaga A (1978) GRP composite materials in construction: properties, applications and durability. Indian Forum 9:27-32

Blaga A (1978) tGRP composite materials in construction: properties, applications and durability, Indian Forum 9:27-32

Bonnet M (2009) Kunststoffe in der Ingenieuranwendung. Vieweg+Teubner, Wiesbaden

Bradley WL, Conroy S (2019) Using Agricultural Waste to Create More Environmentally Friendly and Affordable Products and Help Poor Coconut Farmers. E3S Web of Conferences, 130, 01034. https://doi.org/10.1051/e3sconf/201913001034

Carus M, Eder A, Scholz L (2015). Bioverbundwerkstoffe. Gülzow: Fachagentur für Nachwachsende Rohstoffe e.V. (FNR)

Barbosa D (2017) Accelerated aging effects on carbon fiber/epoxy composites. Compos B Eng 110:298-306. https://doi.org/10. 1016/j.compositesb.2016.11.004

Dhakal H, Bourmaud A, Berzin F, Almansour F, Zhang Z, Shah DU, Beaugrand J (2018) Mechanical properties of leaf sheath date palm fibre waste biomass reinforced polycaprolactone (PCL) biocomposites. Ind Crops Prod 126:394-402. https://doi.org/ 10.1016/j.indcrop.2018.10.044

Fitri SP, Zaman MB, Priyanta D, Hidayat M (2017). Application waste sawdust as mixed polyurethane insulation in traditional cold storage of fishing vessel. International Journal of Marine Engineering Innovation and Research 1. https://doi.org/10. 12962/j25481479.v1i2.1996

Friedrich D, Luible A (2016) Investigations on ageing of wood-plastic composites for outdoor applications: a meta-analysis using empiric data derived from diverse weathering trials. Constr Build Mater 124:1142-1152. https://doi.org/10.1016/j.conbu ildmat.2016.08.123

Gebhardt M, Wanek N, Lemmer A, Gresser GT (2021) Comparison of fibers from hop rich biogas digestate with natural fibers as raw material for composites. J Nat Fibers 1-11. https://doi.org/ $10.1080 / 15440478.2021 .1958426$

Gessner W (1955) Naturfasern-Chemiefasern. Fachbuchverlag, Leipzig

Grundmann E (2007). Faserpflanzen aus ökologischem Anbau Anbau - Verarbeitung - Markt ; Tagungsband, 19. Juni 2007, KasselWilhelmshöhe. Verl. Lebendige Erde, Darmstadt

Kammerhofer PP (2018). Analyse der Haltbarkeit von Werkzeugen aus carbonfaserverstärkten Kunststoffen. phdthesis, Technischen Universität München. 
Knackstedt W (1939). Untersuchung über pflanzliche Bastfasern. Dissertation, Technische Hochschule Carolo-Wilhelmina zu Braunschweig.

Koolen G, van Vuure A (2019). The Effect of Silicone coatings on the Durability of Natural Fiber Compoistes whend subjected to Hygrothermal Aging In R. Fangueiro (ed.), Book of abstracts ICNF 2019: 4th International Conference on Natural Fibers, Smart Sustainable Solutions, 1. 2. 3. july 2019, Porto, Portugal (pp. 64-65). Porto: Tecminho, Associação UniversidadeEmpresa Para o Desenvolvimento

Kotnarowska D (1999) Influence of ultraviolet radiation and aggressive media on epoxy coating degradation. Prog Org Coat 37:149-159. https://doi.org/10.1016/s0300-9440(99)00070-3

Kumar BG, Singh RP, Nakamura T (2002) Degradation of carbon fiber-reinforced epoxy composites by ultraviolet radiation and condensation. J Compos Mater 36:2713-2733. https://doi.org/ $10.1177 / 002199802761675511$

Pschorr FE, Cianciarulo AN (1965) Weathering of epoxy resind systems. Polym Eng Sci

Pufe I (2012) Nachhaltigkeit. UVK Verlagsgesellschaft mbH, München

Rana S, Pichandi S, Parveen S, Fangueiro R (2014) Natural plant fibers: Production, processing, properties and their sustainability parameters. Textile science and clothing technology, Springer Singapore, pp 1-35. https://doi.org/10.1007/978-981-287-065-0_1
Riedel U, Nickel J (2000). Konstruktionswerkstoffe aus nachwachsenden Rohstoffen (BioVerbunde). Tagungshandbuch - 3. Internationale AVK-TV Tagung für Verstärkte Kunststoffe und Duroplastische Formmassen. https://doi.org/10.1002/15214052(200105)32:5<493::aid-mawe493>3.0.co;2-c

Roylance D, Roylance M (1978) Weathering of fiber-reinforced epoxy composites. Polym Eng Sci 78(4)

Sadeghifar H, Ragauskas A (2020). Lignin as a UV light blocker-a review. Polymers 12, 1134. https://doi.org/10.3390/polym12051 134

Sandermann W, Sehlumbom F (1962). Photometrische und chromatographisehe Untersuchungen an Holzmehlen. Holz als Roh- und Werkstoff

Schürmann H (2007). Konstruieren mit Faser-Kunststoff-Verbunden. Springer-Verlag

United Nations (2021) The 17 Goals. Retrieved from https://sdgs.un. org/goals. Accessed 26 Aug 2021

Vogt D (2006) Studie wood plastic composites, Holz-Kunststoff-Verbundwerkstoffe. Landwirtschaftsverl, Münster

Wang Y, Xiao X, Wang S, Li K, Jiang Y, Ma Y (2019) Exploration on UV-blocking performance of lignin from palm (Trachycarpus Fortunei) fiber. J Nat Fibers 18:71-79. https://doi.org/10.1080/ 15440478.2019.1612307 